\title{
Gênio e tragédia: o desaparecimento de Majorana
}

HEN R I QUE FLE M IN G

Leonardo Sciascia escreve sobre a humanidade no contexto siciliano, assim como outros acharam o universal em um sanatório, ou em um dia em Dublin, ou em um copo de vinho. Um cientista siciliano, com trabalhos de relevo na física nuclear, não poderia ficar fora de seu painel, ainda mais com uma vida que admite uma interpretação pirandelliana, se a versão de Sciascia, de que Majorana desapareceu do mundo por ter escoIhido viver outra vida, como Mattia Pascal, se revelar, vier a se revelar, verdadeira.

Ettore Majorana, de ilustre família siciliana, é dotado de talento matemático em escala genial, incluindo-se aí o aspecto circense de ser um prodigioso calculador mental: no futuro encenará competições com Fermi, este armado de uma calculadora, e o baterá muitas vezes. Não encontrará obstáculos à sua carreira científica, que incluirá lauréis de variados tipos: colaboração com Fermi, publicação de trabalhos brilhantes, de valor permanente, colaboração com Heisenberg, cátedra em Nápoles por "clara fama". Uma vez em Nápoles, ainda que dividido, resolve desaparecer, e o faz, talvez de um ferryboat de Palermo. Muita investigação, exigida por Mussolini (são os anos 30), sem resultado. Nem ele nem o corpo são jamais encontrados.

Sobre ele, mas principalmente sobre o seu desaparecimento, escreveu Sciascia um de seus livros mais brilhantes, Majorana Desapareceu, um thriller e uma reflexão a um tempo, uma leitura entusiasmante.

A tragédia de Majorana admite também a interpretação trivial e, ai de mim, provavelmente correta. Introvertido, pessimista, sem amigos e com escândalos graves na família, tendo que se expor a um público nas aulas e de se inserir na vida de Nápoles, tudo ao mesmo tempo pode ter sido demais para ele. Anuncia a morte ao diretor do Instituto de Física (manifestação gritante da falta de um confidente) e, depois, o fracasso da tentativa ("o mar me recusou": encontra forças para esta poesia extrema!). Numa segunda tentativa, acerta. É o que creio.

Muitos não se conformam, seguindo o falso raciocínio de que, se alguma inteligência facilita a vida, uma inteligência superior faz da vida um brinquedo de criança. Sciascia, ele mesmo de inteligência fulgurante, sabe bem que não é assim, e adota para o caso uma explicação alternativa. Veremos mais tarde que não lhe era, realmente, concedida nenhuma alternativa. Escreve então o seu anti-Fausto. Para Sciascia, Majorana, mercê de seu talento clarividente, vislumbra a inevitabilidade da bomba atômica e, à diferença de outros, de Fermi em especial, recusa o pacto. Tem de desaparecer, e, em um país católico, isso é possível, em um claustro. No final tantalizante do livro o monge que guia o escritor pelas escadas do mosteiro surge como uma possibilidade, que cresce rapidamente para uma probabilidade, de ser o próprio Majorana, ou de tudo saber sobre Majorana. E tudo termina, abruptamente, o leitor abandonado e perplexo. É esta a arte do poeta. Vamos agora aos fatos.

Ettore Majorana, após encantar a família com a sua genialidade (que podiam apreciar: seu tio, Quirino Majorana, era um físico que despertou certo interesse por seus estudos experimentais sobre a gravitação), tornou-se aluno de engenharia no Politécnico de Roma. Nessa época dominava o panorama científico italiano Enrico Fermi, jovem fí-

HENRIQUE FLEMING é professor do Instituto de Flsica da USP, no Departamento de Fisica Matemática.

Majorana Desapareceu, Leonardo Sciascia, tradução de Mário Fonbelli, Rio de Janeiro, Rocco, 98 pp. 
sico que, em poucos anos, seria considerado o novo Galileu, na Itália e no mundo. Vários estudantes de engenharia foram atraídos e capturados pelo gênio de Fermi, entre eles Majorana, a quem Fermi considerou seu mais brilhante discípulo. A propósito, tornou-se comum rejeitar em Majorana a condição de discípulo de Fermi, como se isso pudesse de alguma forma diminuir os seus méritos. É um engano. A chegada em cena de Fermi promoveu uma tal revolução na devastada física italiana que todo físico peninsular desde então é justamente considerado seu discípulo.

Em poucos anos atinge Majorana o nível de pesquisador maduro e independente, a par dos demais colaboradores de Fermi, todos destinados à fama, como Franco Rasetti, Enrico Persico, Edoardo Amaldi, Emilio Segrè, Bruno Pontecorvo. Sobre eles paira a autoridade de Fermi, que, além da maestria consumada das técnicas teóricas e experimentais, possuía a raríssima capacidade de adivinhar quais questões científicas se tornariam em breve importantes. Como se pode competir com quem tem acesso ao futuro? Criou-se, dentro do grupo, uma hierarquia modelada na da Santa Sé (estamos em Roma!). Fermi era, também pela infalibilidade, o Sumo Pontífice. Persico, que dava aulas de Mecânica Quântica em Turim, era o Cardeal para a propaganda de Fé. Majorana era o Grande Inquisidor, título motivado tanto pela sua exigência de rigor e conseqüente questionamento sistemático quanto por seu ar grave e misterioso. Essa brincadeira é reveladora e abre o caminho para uma reflexão que tem sido negligenciada. Os físicos costumam ter um comportamento algo infantil, que se acentua nas atividades de grupo. Nasce de exercerem sua atividade em um mundo simplificado, organizado por regras simples. A habilidade do físico é, em larga medida, a habilidade de simplificar, ora um problema, ora um contexto. Muitos dos que vivem felizes nesse ambiente apresentam sintomas do que foi chamado de "protracted infancy". O grupo de Fermi se enquadra muito bem nessa descrição, e esse comentário não é meu, é de Laura Fermi, esposa de Enrico, em seu brilhante livro Atomi in Famiglia. Majorana, ao contrário, era possuidor de ampla e refinada cultura. Fala de Ibsen no bilhete que "retira" o anúncio de seu suicídio iminente. Pensava sobre tudo. Não devia se sentir muito bem entre os "ragazzi di via Panisperna"'. De fato, não era nem mesmo muito assíduo. Em Leipzig encontrou uma alma irmã, Heisenberg. Este sim, servia para ele. Heisenberg lia os fílósofos, às vezes em grego, e se valia deles em seus trabalhos científicos. Deram-se muito bem, ficaram amigos, desperdiçaram seu preciosíssimo tempo em partidas de xadrez. Em tempos mais fáceis Heisenberg ter-lhe-ia oferecido uma posição em seu círculo.

De volta à Itália também esses poucos meses de vida que lhe pareceram aceitáveis ficaram para trás. Para mim o quadro para uma tentativa de supressão, da vida ou "daquela" vida, estava pronto. "Durante quatro anos, do verão de 33 ao verão de 37 , sai raramente de casa e, ainda mais raramente, aparece no Instituto. A um certo ponto deixa de freqüentá-lo."

\section{Majorana, com horror, teria antecipado a "bomba"}

Sciascia se desconcerta com essas pausas. E imagina que não sejam pausas, mas perf́dos de pesquisa intensíssima, febril, sobre algum tópico que o ob æessionava. Supondo que tal portento não pudesse errar (nos dois sentidos da palavra) procura o tema dessas pesquisas no futuro. Qual foi o fato mais clamoroso no reino da física nos anos que se seguiram a esse perfodo? A construção da bomba atômica. Ecco! Majorana a havia antecipado, e isso o horrorizara. O motivo para o desaparecimento estava achado, mas não servia para a morte. A crônica de Majorana passava a fazer sentido. Sim, ou não?

Acho que não. Sei que não!

Quatro anos de isolamento, para um físico, não o aproximam do conhecimento da natureza, antes o distanciam, às vezes de maneira irreversível. A introspecção não e um instrumento eficiente de pesquisa do mundo físico. Em particular naquela época, e em relação ao tema em questão. Não havia uma teoria do núcleo atômico, cujas conseqüências pudessem ser exploradas no silêncio do seu ateliê e na profundidade de suas reflexões. A f́́sica nuclear consistia em uma tarefa social, em que experiências forneciam fragmentos que resistiam às tentativas de compor um mosaico completo. De uma parte $\mathrm{e}$ de outra vinham esses fragmentos, e as idéias que suscitavam muitas vezes nem chegavam a ser escritas, criando um saber oral só acessivel àqueles que praticavam constantemente esse comércio de dados e idéias. A solidão estiola, o que ficou claro no caso do gênio dos gênios, Albert Einstein. Na filosofia natural o Zaratustra que desce das montanhas nada tem a anunciar. A época era de rascunhos de trabalhos que circulavam de 
mão em mão (não havia tempo de esperar a publicação), de participação em congressos improvisados no último minuto... Estava se descobrindo o que era o núcleo. Nessa epoca, Sir Ernest Rutherford, o descobridor do núcleo, a par de tudo o que acontecia, como editor da revista Nature, consultado sobre a viabilidade de se extrair energia do átomo, qualificou a idéia de "sonho". É claro que qualquer diletante poderia ter dito o contrário, e ser considerado profético, quando estaria sendo só leviano. E Majorana não era leviano. Muito ao contrário, era serí́ssimo, sério como um filósofo, no dizer de Ortega y Gasset.

Estava-se muito longe disso. Faltava, por exemplo, a idéia da reação em cadeia. E se não faltasse, por paradoxal que possa parecer, a extração de energia do átomo pareceria ainda mais distante. Pois quem poderia prever o alcance dessa cadeia: queimaria toda a atmosfera? Foi preciso muito tirocinio, e um físico cuidadosíssimo para, vários anos depois, já em pleno projeto Manhattan, concluir pela segurança do projeto. Majorana, nem ninguém, poderia ter realizado todos esses passos sozinho, de seu apartamento romano.

Não creio, na realidade, que Sciascia tenha sido totalmente sincero ao defender sua tese. Era um romancista ("hypocrite auteur"), e seu ofício era a alma humana. $\mathrm{O}$ fio que escolheu o levava mais a fundo neste tema. Estava, na época em que escrevia o livro, chocado com os físicos. Em $\mathrm{Ne}$ ro su Nero, uma espécie de diário que recolhe trechos de seus artigos em jornais, relata sua entrevista com um físico eminente, talvez Edoardo Amaldi. "Janto com um físico. Em silêncio ouço seus discursos sobre a ciência. Perturbado a princípio, depois aniquilado. Saindo, surpreendo-me a repetir a frase de Matteotti, ao descer do trem que o trazia de volta da Rússia: - Horror, meus amigos, horror." Não podia admitir que o seu Majorana fosse assim (e não o era!). A inteligência é confiável, ou; como se diz sobre a graça, é eficaz? O Majorana de Sciascia diz que sim, desde que em grau superior.

Nas páginas do Corriere della Sera o autor prefigura o livro que lhe seria possivel escrever: “ - Está escrevendo um livro? pergunta-me o camponês. Ouviu por toda a manhã o tic-tac da máquina de escrever: agora desci para um café em companhia deles. São dois: um taciturno, irónico no olhar; o outro loquaz, sentencioso, oracular.

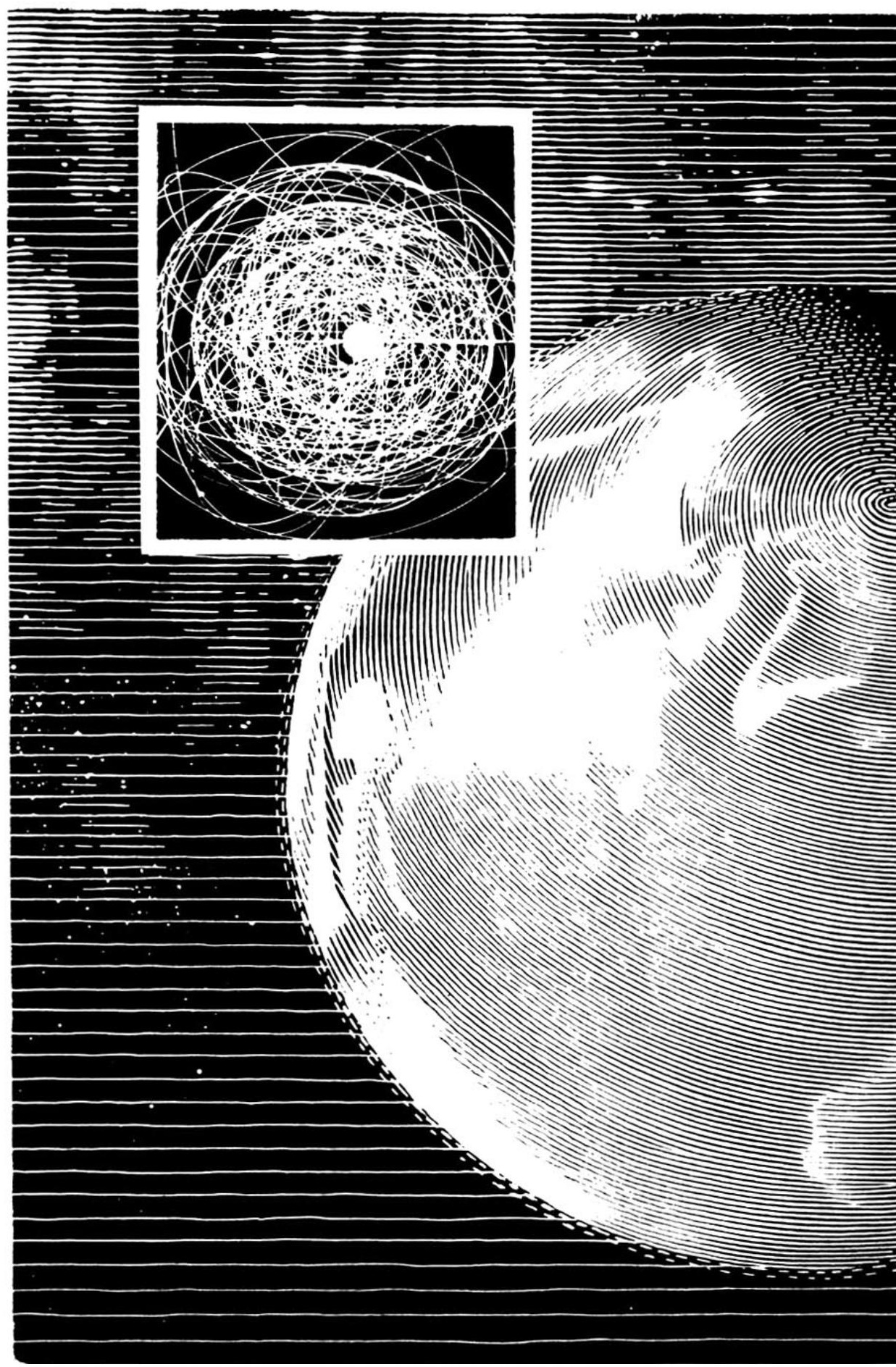
E sem esperar minha resposta, o loquaz me dá esta receita: - Um livro está todo em como termina. O fim deve ser espantoso. E deve haver um rei. Se soubesse ler, ou se o lessem para ele, talvez não reconhecesse esses elementos no livro que estou escrevendo - ainda que lá estejam. Ele está simplesmente reinventando a tragédia, aquela que seus semelhantes de mais de dois mil anos atrás pediam a Ésquilo e a Sófocles, a quem ouviam nos teatros entre os olivais, diante do mar".

A história de Majorana tem um final espantoso, e o poeta escolheu a versão que introduziu um rei. 